\title{
PURIFICATION AND CYTOTOXICITY STUDY OF LOVASTATIN FROM SOIL FUNGI
}

\author{
BALRAJ JANANI ${ }^{1}$, GANESAN SAIBABA ${ }^{2}$, GOVINDARAJU ARCHUNAN ${ }^{2}$, KALIESWARAN VIDHYA ${ }^{1}$, JAIRAMAN \\ KARUNYADEVI ${ }^{1}$, JAYARAMAN ANGAYARKANNI ${ }^{1 *}$
}

${ }^{1}$ Department of Microbial Biotechnology, Bharathiar University, Coimbatore, Tamil Nadu, India. ${ }^{2}$ Department of Animal Science, Bharathidasan University, Trichirapalli, Tamil Nadu, India. Email: angaibiotech@buc.edu.in

Received: 18 May 2017, Revised and Accepted: 30 June 2017

\section{ABSTRACT}

Objective: The objective of the present study is to evaluate the anticancer potential of lovastatin obtained from fungal source.

Methods: About 15 fungal cultures were isolated from soil samples collected from Bharathiar University, India, and all are identified and characterized through microscopic characterization. Lovastatin producing capability was confirmed through bioassay against Saccharomyces cerevisiae, and the ability of selected fungus to produce lovastatin was further confirmed by high-performance liquid chromatography. Maximum lovastatin producing fungi were further selected for purification (overloaded elution chromatography) and characterization done using inhibition rate (IR). 5-diphenyl tetrazolium bromide (MTT) assay using A549 cell line was performed for antitumor activity evaluation.

Results: Among the 15 isolates, Aspergillus flavus exhibited the maximum zone of inhibition (1.5 cm) against the test organism through solid-state fermentation. The resemblance in retention time (RT) of peak shown in chromatograms of standard lovastatin (RT=25.1 minutes) and sample (RT=25.1 minutes) were similar. This confirmed the presence of lovastatin in the selected fungal isolate (A. flavus). The presence of two functional groups in lovastatin $\mathrm{C}=\mathrm{O}$ and $\mathrm{O}-\mathrm{H}$ was confirmed by IR spectrum $50 \%$ of cell lysis was observed in MTT assay.

Conclusion: Lovastatin obtained from soil fungi is capable of producing lovastatin in good proportions. Obtained fungal lovastatin exhibited significant antitumor activity against A549 cell line. Like other biological derivatives, lovastatin from soil fungi had greater potential in anticancer activity, and further biosynthetic pathway insights in their production can improve the yield which aid in large scale production.

Keywords: High-performance liquid chromatography, 3-hydroxy-3-methylglutaryl coenzyme A reductase, Lovastatin, Inhibition rate, 5-diphenyl tetrazolium bromide.

(C) 2017 The Authors. Published by Innovare Academic Sciences Pvt Ltd. This is an open access article under the CC BY license (http://creativecommons. org/licenses/by/4. 0/) DOI: http://dx.doi.org/10.22159/ajpcr.2017.v10i10.20075

\section{INTRODUCTION}

Fungi were once looked out as a source for the variety of enzymes but now they are exploited for its secondary metabolites too. The complex metabolic pathways in fungal cells favor the production of different types of secondary metabolites which have high pharmacological value. The secondary metabolites include antibiotics, pigments, toxins, antitumor agents, immune modulating agents, receptor antagonists, and pesticides. They have a major effect on the health, nutrition, and economy of our society. They are often unusual structures and their formation is regulated by nutrition, growth rate, feedback control, enzyme inactivation, and enzyme induction.

Polyketides constitute the largest class of fungal secondary metabolites. They are generally found in soil microorganisms and there are more than 7000 known polyketides. The large arrays of structurally diverse polyketide produced by microorganisms originate from repetitive connections of short-chain fatty acids, for example, acetate or propionate by pathways very similar to those of fatty acid biosynthesis [1]. Polyketides were a rich source of many pharmaceuticals including antibiotics, anticancer drugs, cholesterol lowering drugs, immunosuppressants, and other therapeutics. Out of the very important classes of polyketides is "statin" which includes lovastatin, mevastatin, and pravastatin.

Lovastatin, also known as monacolin, is a kind of fungal metabolite, serving as a competitive inhibitor of 3-hydroxy-3-methylglutaryl coenzyme A reductase, the rate-limiting enzyme in cholesterol biosynthesis [2]. It can effectively reduce plasma cholesterol levels in various mammalian species including human and hence they are effective in the treatment of hypercholesterolemia. Lovastatin and its semi-synthetic derivatives are very important drugs to treat heart disease. Lovastatin was produced by several fungal species including Monascus purpureus, Monascus ruber, Monascus pilosus, Monascus pubigerus, Monascus vitreus, [2-4] and Aspergillus terreus [5-11]. The commercial production of lovastatin is mainly through submerged fermentation of $A$. terreus $[12,13]$. Lovastatin is an intracellular product and is mostly accumulated in mycelia. In submerged fermentation, its yield is proportional to the amount of biomass, with the high cell density and hence viscosity of the fermentation broth increases and there was a difficulty in stirring and oxygen mass transfer; an alternative strategy to produce lovastatin is by solid-state fermentation (SSF) process. Despite the low substrate cost and low energy consumption, the SSF can offer a good environment for fungi to grow; therefore, high mycelia density and high lovastatin production can be expected [14-20].

Recent evidence showed that statins not only reduce the mortality of cardiac diseases but also the incidence of cancer up to 28-33\% [21]. Lovastatin had shown great promise beyond their well-documented lipid lowering effects and they also suppress a variety of leukemic cell lines and a wide array of solid tumor cells in vivo, by inhibiting the synthesis of non-sterol isoprenoid compounds [22]. Owing to the beneficial aspects of lovastatin, an attempt was made in this study to screen and characterize lovastatin producing fungi from the soil sample.

\section{METHODS}

Microorganism and inoculum preparation

Filamentous fungi were isolated from soil samples collected from Bharathiar university campus, Coimbatore, India. Isolation of desired 
fungal cultures were initially isolated by plating collected soil samples on potato dextrose agar (PDA) and characterized by following standard microbial methods such as morphological and microscopic properties. Individual colonies of microfungi were picked and purified by streaking onto fresh PDA medium. The pure fungal isolates were kept on PDA medium at $4{ }^{\circ} \mathrm{C}$ and recultured every 4 weeks. For preparing a spore suspension, towel sporulated PDA slants of isolates, $10 \mathrm{ml}$ spores suspension medium $(0.9 \% \mathrm{NaCl}, 0.1 \%$ Tween 80$)$ was added. The surface was scrapped with a loop and suspension was collected. The suspension was agitated thoroughly using cyclomixer to suspend the spore and filtered through a glasswool. The concentration of the spore suspension was measured using an hemocytometer and adjusted to $1 \times 10^{8}$ spores $/ \mathrm{ml}$ which was used as inoculum throughout the study [23].

\section{Media and cultivation conditions}

To screen the potent lovastatin producing fungal strain, lovastatin production was carried out using isolated fungal strains through SSF. In the fungal fermentation, solid substrate (wheat bran; particle size 0.3-0.5 mm) was dried in an oven at $60^{\circ} \mathrm{C}$, accurately weighed to $8 \mathrm{~g}$ in Petri plates (100 mm x $17 \mathrm{~mm})$, appropriately moistened with $0.8 \mathrm{ml}(10 \% \mathrm{v} / \mathrm{w})$ of spore suspension. The medium (glucose $[20 \mathrm{~g} / \mathrm{l}]$, lactose [20 g/l], Na-glutamate [12.5 g/l], $\mathrm{KH}_{2} \mathrm{PO}_{4}[5 \mathrm{~g} / \mathrm{l}], \mathrm{K}_{2} \mathrm{HPO}_{4}[5 \mathrm{~g} / \mathrm{l}]$, $\mathrm{FeSO}_{4} \cdot 7 \mathrm{H}_{2} \mathrm{O}[0.2 \mathrm{~g} / \mathrm{l}], \mathrm{MnSO}_{4} \cdot 4 \mathrm{H}_{2} 0[0.1 \mathrm{~g} / \mathrm{l}], \mathrm{ZnSO}_{4} \cdot 7 \mathrm{H}_{2} \mathrm{O}[0.2 \mathrm{~g} / \mathrm{l}]$, $\mathrm{MgSO}_{4} \cdot 7 \mathrm{H}_{2} \mathrm{O}[0.1 \mathrm{~g} / \mathrm{l}], \mathrm{CaCl}_{2} \cdot 2 \mathrm{H}_{2} \mathrm{O}[20 \mathrm{mg} / \mathrm{l}], \mathrm{CuCl}_{2} \cdot 2 \mathrm{H}_{2} \mathrm{O}[5 / \mathrm{mg} / \mathrm{lit}]$, $\mathrm{H}_{3} \mathrm{BO}_{3}[11 \mathrm{mg} / \mathrm{l}],\left(\mathrm{NH}_{4}\right) 6 \mathrm{Mo}_{7} \mathrm{O}_{24} \cdot 4 \mathrm{H}_{2} \mathrm{O}[5 \mathrm{mg} / \mathrm{l}], \mathrm{pH}$ adjusted to 6.5$)$ was thoroughly mixed and incubated at $30^{\circ} \mathrm{C}$, in a humidity-controlled incubator for 7 days. After incubation, the fungal cultures were harvested and analyzed for presence of lovastatin $[17,24]$.

\section{Extraction of lovastatin from the culture media}

Fermented material was dried at $40^{\circ} \mathrm{C}$ for $24 \mathrm{hrs}$, crushed to powder, and $2 \mathrm{~g}$ of the powdered material was extracted by $100 \mathrm{ml}$ of methanolwater mixture $(1: 1 \mathrm{v} / \mathrm{v})$ at $\mathrm{pH} 7.7 \mathrm{in} 250 \mathrm{ml}$ Erlenmeyer flask, keeping the flask at $30^{\circ} \mathrm{C}$ in the rotary shaker at $200 \mathrm{rpm}$ for $2 \mathrm{hrs}$. After $2 \mathrm{hrs}$, the mixture was centrifuged at $10,000 \mathrm{rpm}$ for 10 minutes, and the supernatant was filtered through $0.45 \mu \mathrm{m}$ membrane filter [17].

\section{Lovastatin detection}

The bioassay method for screening the lovastatin producing fungi was adopted from Kumar et al. (2000) [25] and Vilches et al. (2005) [26] using Saccharomyces cerevisiae as indicator organisms, and the ability of lovastatin to inhibit fungal growth was tested. Yeast growth inhibition was performed by seeding $15 \mathrm{ml}$ of glucose yeast peptone agar medium with $0.25 \mathrm{ml}$ of yeast culture (S. cerevisiae). Yeast inoculated medium was poured into a $15 \mathrm{~cm}$ diameter glass Petri dish. After solidifying, $6 \mathrm{~mm}$ diameter wells were made with aid of sterile cork borer. Two different volumes of the crude extracts $(25$ and $50 \mu \mathrm{L})$ were taken and transferred to these wells. Methanol-water mixture $(1: 1 \mathrm{v} / \mathrm{v})$ and standard solution of lovastatin were used as negative and positive controls, respectively. Plates were incubated at $26^{\circ} \mathrm{C}$ for $16 \mathrm{hrs}$ and afterward inhibition zone were measured [27]

\section{Estimation of lovastatin}

Lovastatin in the clear extract was estimated by high-performance liquid chromatography (HPLC) system (Agilent1100series) using C-18 (250 mm length $\times 4.6 \mathrm{~mm}$ ID). A mixture of $0.02 \mathrm{M}$ phosphate buffer (pH7.7) and acetonitrile in a ratio of $65: 35(\mathrm{v} / \mathrm{v})$ was used as mobile phase. The $20 \mu \mathrm{l}$ sample was injected, the eluent flow rate was $1.0 \mathrm{ml} /$ minutes, and the detection wavelength was $238 \mathrm{~nm}$. The identity of the compound was confirmed with an authentic lovastatin (SigmaAldrich) reference standard [17].

\section{Purification of lovastatin}

In the fermentation broth, lovastatin is present mostly in its hydroxyacid form and mevinolinic acid. The isolation of mevinolinic acid from the fermentation broth was done by solvent extraction using methanol: Water mixture $(1: 1 \mathrm{v} / \mathrm{v})$ at $\mathrm{pH}$ 7.7. The extract is concentrated by vacuum distillation at $106^{\circ} \mathrm{C}$ for $2 \mathrm{hr}$. The concentrated extract was subjected to column chromatography (Silica 60-120 mesh was activated and packed tightly into the $60 \mathrm{~cm} \times 3.5 \mathrm{~cm}$ size column chromatography without air bubbles) using solvents $n$-hexane and petroleum ether mixture $(1: 1 \mathrm{v} / \mathrm{v})$. White powder was obtained by subsequent evaporation of solvents [4]

\section{Infrared spectrometry}

A pinch of $\mathrm{KBr}$ pellet was oven-dried and transferred into a mortar. The purified sample at about $0.1-2 \%$ was added, mixed, and ground to a fine powder. The mid-range inhibition rate (IR) spectra, 4000-400 $\mathrm{cm}^{-1}$ were recorded on a Nicolet Avatar Model fourier transform infrared spectrophotometer [28].

\section{Cytotoxicity assay}

Cytotoxicity evaluation of secondary metabolites was performed using 3-(4,5-dimethylthiozol-2-yl)-2,5-diphenyl tetrazolium bromide (MTT) assay as described by Ghasemi-Mobarakeh et al. (2008) [29]. A549 cells were trypsinized, and 5000 cells were seeded in a flat-bottomed 96-well polystyrene-coated plate and were incubated for $24 \mathrm{hrs}$. Different concentrations of commercial lovastatin and lovastatin from fungal extract (purified fraction) were prepared in Dulbecco's modified Eagle's medium with $5 \%$ fetal bovine serum. The viability of the cells treated with different concentrations of commercial lovastatin and lovastatin from fungal extract was estimated after $48 \mathrm{hrs}$ of incubation. Optical density was read at $570 \mathrm{~nm}$ using 96-well Multiskan ${ }^{\text {TM }} \mathrm{GO}$ microplate spectrophotometer (Thermo Scientific, USA). The cells were given with 2,4 , and $6 \mu \mathrm{g} / \mathrm{ml}$ of lovastatin and cells without any treatment were used as a control. The experiment was done in triplicates (mean \pm standard deviation).

\section{RESULTS}

\section{Isolation of fungal cultures}

The aim of this study was to find a better filamentous fungus for lovastatin production compared to already available fungi. Nine pure cultures of fungus were isolated from the soil sample collected in the campus of Bharathiar University by serial dilution technique on sabourad dextrose agar. They were characterized using standard microbiological methods such as morphological and microscopic characteristics. Characterized and identified fungal cultures (1) Aspergillus sp.1, (2) Fusarium sp., (3) Aspergillus sp.2, (4) Aspergillus sp.3, (5) Aspergillus niger, (6) Aspergillus fumigatus, (7) Aspergillus oryzae, (8) Aspergillus flavus, and (9) Rhizopus sp. were maintained as pure cultures on PDA slants at $4^{\circ} \mathrm{C}$. The isolates were further analyzed for their potential lovastatin production.

\section{SSF and downstream processing of lovastatin}

All the nine fungal strains were grown under SSF to screen their potential for lovastatin production. At the end of 7 days of fermentation, organic phase containing lovastatin was extracted through solventsolvent extraction. Then, crude extract was concentrated by drying at room temperature for further analysis.

\section{Screening of isolates for lovastatin production through bioassay} method

The results of bioassay revealed that out of nine, six isolates fungal cultures showed zone of inhibition for yeast $S$. cerevisiae. Based on the diameter of inhibition zone $(\mathrm{cm})$ obtained with two different concentrations of standard and fungal extracts, it has been observed that maximum lovastatin production was found with A. flavus. The other fungal isolates with decreasing order of their lovastatin producing potential are Aspergillus sp.1, Aspergillus sp.2, Aspergillus sp.3, A. fumigatus, and A. oryzae (Fig. 1). A clear inhibition zone around the indicator organisms was the basis for the selection of suitable fungal strains for production of lovastatin.

\section{Confirmation and quantification of lovastatin by HPLC}

To ensure whether the maximum zone of inhibition exhibited by isolate (A. flavus) on bioassay plates were due to lovastatin activity, the crude extract were subjected to HPLC for quantitatively confirming the amount of lovastatin in the fungal extract. Analysis of lovastatin 
in HPLC confirmed its identity with that of authentic lovastatin. The resemblance in retention time (RT) of peak shown in chromatograms of standard lovastatin ( $\mathrm{RT}=25.1$ minutes) and sample ( $\mathrm{RT}=25.1$ minutes) were similar (Fig. 2a and b). This confirmed the presence of lovastatin. Lovastatin quantification was carried out on A. flavus extract (Table 1). These analytical procedures confirmed the production of lovastatin in the selected fungal isolate (A. flavus).

\section{Purification of lovastatin}

To use lovastatin as a drug at commercial level, measures have to be taken to ensure that the final product is not only in its purest form but also shows no loss of activity on purification and is safe for human consumption. Lovastatin extracted from $A$. flavus on the $7^{\text {th }}$ day of solid fermentation was subjected to column chromatography. The extract is concentrated by vacuum distillation at $106^{\circ} \mathrm{C}$ for 2 hrs and then poured into the packed activated silica, and the fractions were eluted by solvents benzene and acetonitrile in the ratio 1:1. Ninety fractions were collected (flow rate $1 \mathrm{ml} /$ minute) and all collected fractions were dried using vacuum evaporator. Up to 60 fractions, yellow colored eluent was obtained, which were then followed by watery colored eluent. These watery colored eluents were checked for their purity of lovastatin by HPLC analysis. The fractions from 61 to 66 showed the presence of lovastatin. All the 6 fractions were analyzed by HPLC, and the fraction 64 showed the presence of pure lovastatin and the experiment was conducted thrice to standardize the purification process.

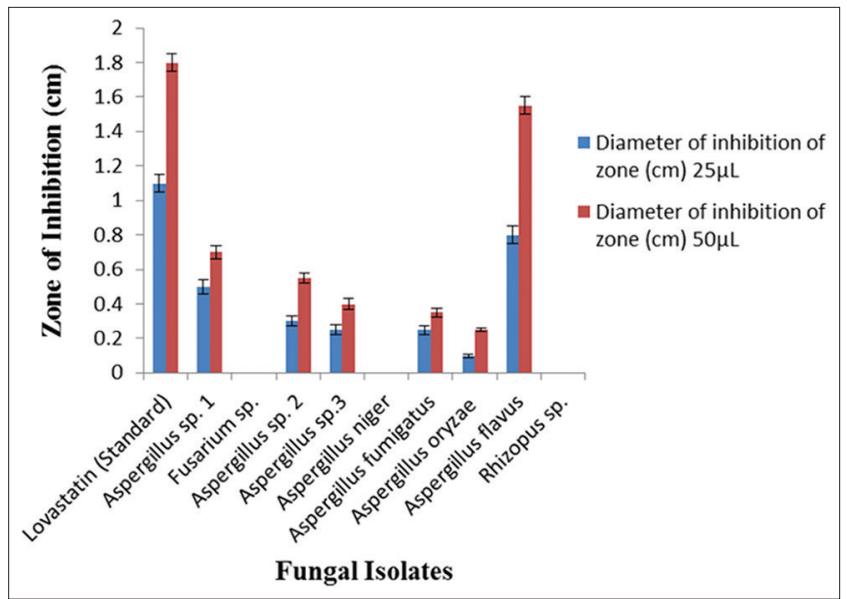

Fig. 1: Screening of lovastatin producing fungal isolates through bioassay

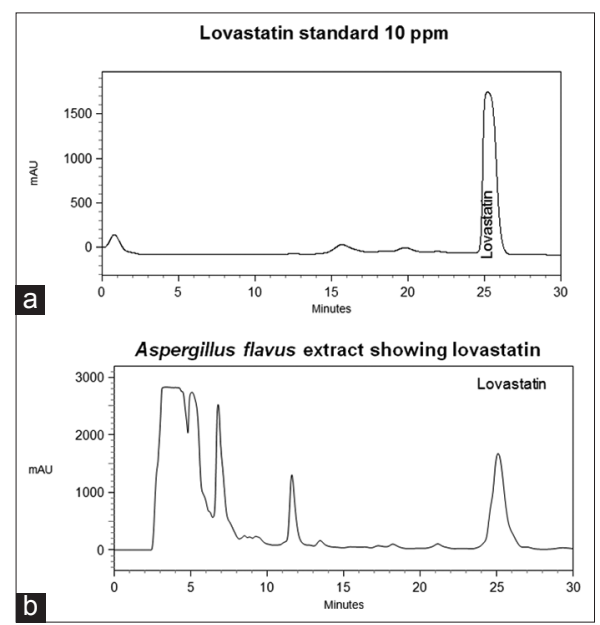

Fig. 2: (a) High-performance liquid chromatography chromatogram of standard, (b) high-performance liquid chromatography chromatogram of lovastatin production in Aspergillus flavus
Structure analysis

The purified lovastatin obtained after column chromatography process was confirmed by IR spectrum. IR spectrum was recorded on Shimadzu spectrometer, and the absorption frequencies are expressed in reciprocal $\left(\mathrm{cm}^{-1}\right)$. IR spectrum showed stretching at 1633 and $1643 \mathrm{~cm}^{-1}$ and indicating the presence of two $\mathrm{C}=0$ groups. A broadband between 3369 and $3498 \mathrm{~cm}^{-1}$ showed the presence of $\mathrm{O}-\mathrm{H}$ group. The presence of two functional groups in lovastatin $\mathrm{C}=\mathrm{O}$ and $\mathrm{O}-\mathrm{H}$ was confirmed by IR spectrum (Fig. 3).

\section{Cytotoxicity assay}

The purified lovastatin showed cytotoxicity against A549 cells lines in a dose-dependent manner (Fig. 4). The effective concentration for $50 \%$ cell death (half maximal inhibitory concentration inhibitory concentration) was found to be $30 \pm 5 \mu \mathrm{g} / \mathrm{ml}$. This result indicated that lovastatin from fungal extract (A. flavus) is a strong cytotoxic agent which partially explains its antitumor activity than authentic lovastatin.

\section{DISCUSSION}

Lovastatin is widely used as an anticholesterolemic drug, and researchers have screened several microbes for lovastatin production from various niches [30]. Soil is the exceptionally rich source for potential drug producing organisms, especially for fungi. Therefore, in the present study, attempts were made to isolate potential of lovastatin producing fungal strains from soil sample collected from campus of Bharathiar University, Coimbatore, India, which is described as the culture of choice for the production of lovastatin [5]. The identified fungal isolates belonged to different classes such as Aspergillus sp.1, Fusarium sp., Aspergillus sp.2, Aspergillus sp.3, A. niger, A. fumigatus, A. oryzae, A. flavus, and Rhizopus sp. In this, majority of

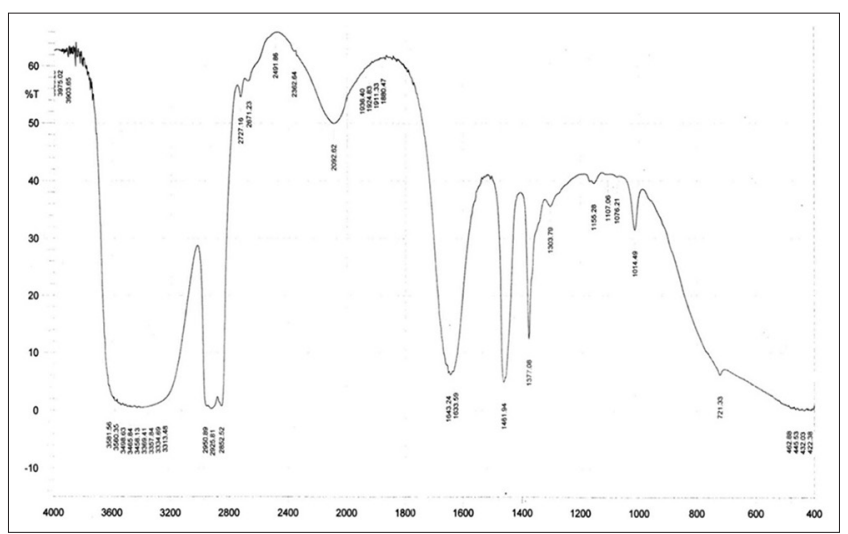

Fig. 3: Inhibition rate spectrum of purified lovastatin

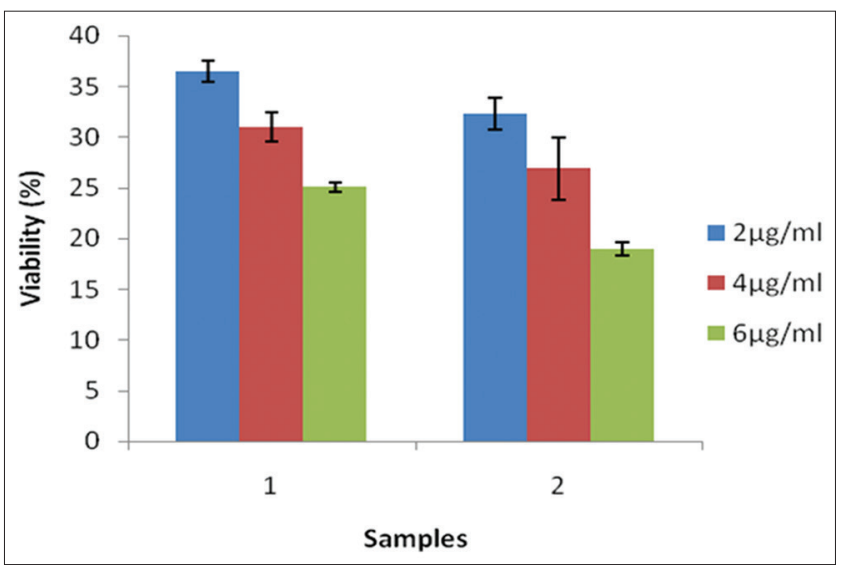

Fig. 4: Cytotoxicity assay after 48 hrs (mean \pm standard deviation) Sample 1: Lovastatin from fungal extract. Sample 2: Commercial lovastatin 
Table 1: Production of lovastatin in A. flavus (crude extract)

\begin{tabular}{llll}
\hline Sample & Area & Height & Lovastatin conc. in $\mathbf{~ m g} / \mathbf{g}$ \\
\hline Standard & 439303 & 25053 & 1 \\
A. flavus & 234875 & 8542 & $0.33 \pm 0.02$ \\
\hline \multicolumn{2}{l}{ Mean of three replicates, A. flavus: Aspergillus flavus }
\end{tabular}

Mean of three replicates, A. flavus: Aspergillus flavus

the fungal isolates obtained were Aspergillus sp. strains [31-33]. All these species are known to produce vast array of the primary and secondary metabolites [34]. In recent days, SSF appears to be one of the best choices for any metabolite production using cheaper raw materials $[7,35,36]$. The solid substrates used in SSF are generally insoluble in water and play a dual role by supplying of nutrients and providing anchorage to the cells [37]. Szakacs et al. (1998) reported that production of lovastatin through SSF is superior than submerged fermentation. They observed the highest production of lovastatin using solid substrates such as wheat bran amended with the nutrient solution. Wheat bran has been previously reported as a best suitable carbon source for lovastatin production using A. flavus and A. terreus $[17,38]$. Hence, in the present study, wheat bran was used as the solid substrate for both the fungal sporulation and lovastatin production by isolated fungal cultures. The fungal cultures were grown under SSF conditions to screen their potential for lovastatin production. The lovastatin yield increased rapidly from day 3 to day 5, which explained that although lovastatin is a secondary metabolite and its accumulation in mycelia seems growth related. The maximum lovastatin yield was achieved on day 7 after then the yield was almost unchanged. From the above results, it is obvious that the SSF can be ended at day 7. Because lovastatin is an intracellular product and its accumulation is almost simultaneously with cell growth [39].

The culture extracts prepared in methanol: Water mixture was screened for lovastatin production by employing bioassay against S. cerevisiae. Similar approaches have also been reported using Candida albicans and Neurospora crassa as test organisms [27,40-42] as a less expensive and alternative method for lovastatin assay. These yeasts form constricted colonies on agar and served as a relatively convenient method as compared to using $N$. crassa that shows profuse sporulation. The mechanism of antiyeast inhibition could be attributed to (i) mycosin contact directly with the sterol in the cell membrane causing leakage of cell membrane and the loss of intracellular component, (ii) mycosin attached with ribonucleic acid and inhibition of protein synthesis, and (iii) mycosin inhibited ergosterol synthesis causing increase of membrane permeability and membrane damage [43]. From results obtained during the present study, six out of nine isolates have exhibited the inhibition zone on bioassay plate. Of these, one isolate has exhibited maximum inhibition zone of $1.5 \mathrm{~cm}$ in $50 \mu \mathrm{l}$ concentration and hence it was considered as good lovastatin producer. To ensure whether the zones of inhibition exhibited by A. flavus in bioassay studies were due to lovastatin activity, the crude extract was subjected to HPLC for further confirmation and estimation of lovastatin. Analysis of lovastatin in HPLC is carried out in the form of $\beta$-hydroxyacid form. Because the $\beta$-hydroxyacid form elutes earlier in the chromatographic column $[44,45]$. And also, the fermentation liquor chiefly contains lovastatin in the form of $\beta$-hydroxyacid. The chromatogram reveals that RT of standard lovastatin and sample was 25.1 minutes and 25.1 minutes, respectively. The concentration of crude extract of lovastatin was found to be $0.33 \mathrm{mg} / \mathrm{g}$. Therefore, on the basis of results observed on the bioassay plates and HPLC, it was considered that the strain A. flavus as a potential lovastatin producing candidate for further studies. In accordance with our results, $A$. flavus was considered as the best producer of lovastatin in addition to A. terreus and other fungi [5,46-48]. Similar results have been reported by other investigators for different fungal species [49-51]. The purity of the lovastatin extracted could be enhanced through column chromatography, which employs silica gel as the stationary phase and an eluent system comprising benzene and acetonitrile. Similar to our results, Nidhiya et al. (2012) reported that purification of lovastatin was carried using silica gel- based column chromatography with benzene and acetonitrile used as eluents. In organic solvent extraction of lovastatin by Pansuriya and Singhal (2010) [52] initially, various solvents were screened such as acetonitrile, methanol, ethyl acetate, butyl acetate, toluene, and chloroform for maximum recovery of lovastatin. Acetonitrile gave maximum extraction of both hydroxyl acid and lactone lovastatin which was similar to the results of our present study. The purified lovastatin obtained after column chromatography process was characterized by IR spectrum. The presence of two functional groups in lovastatin $\mathrm{C}=\mathrm{O}$ and $\mathrm{O}-\mathrm{H}$ was confirmed by IR spectrum. The IR spectral data of lovastatin was found to be in concurrence with earlier reported spectral data [53,54]. Although statin has been extensively researched on its property of treating hypercholesterol, several reports suggest that cancer incidence of cancer is also reduced by 28-33\% [21]. Cytotoxicity is one of the properties of antitumor agents [55]. Hence in this study, MTT assay results indicate that lovastatin from fungal extract is a strong cytotoxic agent which partially explains its antitumor activity than commercial lovastatin. Our results are also in accordance with myeloma researchers who had used chemotherapeutic agents in combination with statins [56] and other dose-dependent studies [57]. Hence, it can be suggested for therapeutic use as a cancer chemopreventive agent.

\section{CONCLUSION}

An attempt is made in this study to isolate and screen the lovastatin producing fungi from soil source. The present study shows among the isolated strains, A. flavus yield more lovastatin than the other isolates based on the bioassay result. Analysis of lovastatin in HPLC confirmed its identity with that of authentic lovastatin and it is characterized by IR spectrum. The characterized lovastatin was analyzed for antitumor activity by MTT assay using A549 cell line. Therefore, it could be concluded that compared to A. terreus which is commercially exploited for lovastatin production, the levels of lovastatin isolated from $A$. flavus are comparatively lower. Based on these findings, the future work is aimed at biosynthesis of lovastatin by this fungus could be manipulated to yield greater quantities so that the fungus can serve as a potential source for industrial exploitation.

\section{ACKNOWLEDGMENT}

The corresponding author thank Department of Science and Technology (SR/SO/HS-0131/2008; dt: 28/10/2009) for the financial support. Dr. Govindaraju Archunan acknowledges with thanks to University Grants Commission, New Delhi for the award of UGC-BSR faculty fellow. The instrumentation facility availed from UGC-SAP-II and DST-PURSE programmes, Bharathidasan University is gratefully acknowledged.

\section{REFERENCES}

1. Sivasithamparam K, Ghisalberti EL. Secondary metabolism in Trichoderma and Gliocladium. In: Trichoderma and Gliocladium Basic Biology Taxonomy and Genetics. Vol. 1. London, UK: Taylor \& Francis Group; 1998. p. 139-91.

2. Endo A. Monacolin K. A new hypocholesterolemic agent produced by a Monascus species. J Antibiot (Tokyo) 1979;32(8):852-4

3. Negishi S, Huang ZC, Hasumi K, Murakawa S. Productivity of monacolin K (mevinolin) in the genus Monascus. J Ferment Eng 1986;64:509-11.

4. Manzoni M, Rollini M, Bergomi S, Cavazzoni V. Production and purification of statins from Aspergillus terreus strains. Biotechnol Technol 1998;12(7):529-32.

5. Alberts AW, Chen J, Kuron G, Hunt V, Huff J, Hoffman C, et al. Mevinolin: A highly potent competitive inhibitor of hydroxymethylglutaryl-coenzyme a reeducates and a cholesterollowering agent. Proc Natl Acad Sci U S A 1980;77(7):3957-61.

6. Novak N, Gerdin S, Berovic M. Increased lovastatin formation by Aspergillus terreus using repeated fed-batch process. Biotechnol Lett 1997;19(10):947-8.

7. Szakács G, Morovján G, Tengerdy RP. Production of lovastatin by a wild strain of Aspergillus terreus. Biotechnol Lett 1998;20(4):411-5.

8. Rodriguez Porcel EM, Casas Lopez JL, Sanchez Perez JA, Chisti Y. Enhanced production of lovastatin in a bubble column by Aspergillus 
terreus using a two-stage feeding strategy. J Chem Technol Biotechnol 2007;82(1):58-64.

9. Bizukojc M, Ledakowicz S. A macro kinetic modeling of the biosynthesis of lovastatin by Aspergillus terreus. J Biotechnol 2007;130(4):422-35.

10. Jia Z, Zhang X, Zhao Y, Cao X. Enhancement of lovastatin production by supplementing polyketide antibiotics to the submerged culture of Aspergillus terreus. Appl Biochem Biotechnol 2010;160(7):2014-25.

11. Upendra RS, Khandelwal P. Physical mutagenesis based strain improvement of Aspergillus sp. For enhanced production of lovastatin. Int J Pharm Pharmsci 2016;8(7):163-7.

12. Lopez JC, Pérez JS, Sevilla JF, Fernández FA, Grima EM, Chisti Y. Production of lovastatin by Aspergillus terreus: Effects of the C: $\mathrm{N}$ ratio and the principal nutrients on growth and metabolite production. Enzyme Microb Technol 2003;33(2):270-7.

13. Radha KV, Lakshmanan D. A review: Lovastatin production and applications. Asian J Pharm Clin Res 2013;6(3):21-6.

14. Balakrishnan K, Pandey A. Production of biologically active secondary metabolites in solid state fermentation. J Sci Ind Res 1996;55(5-6):365-72.

15. Robinson T, Singh D, Nigam P. Solid-state fermentation: A promising microbial technology for secondary metabolite production. Appl Microbiol Biotechnol 2001;55(3):284-9.

16. Hölker U, Lenz J. Solid-state fermentation. are there any biotechnological advantages? Curr Opin Microbiol 2005;8(3):301-6.

17. Valera HR, Gomes J, Lakshmi S, Gururaja R, Suryanarayan S, Kumar D. Lovastatin production by solid state fermentation using Aspergillus flavipes. Enzyme Microb Technol 2005;37(5):521-6.

18. Xu BJ, Wang QJ, Jia XQ, Sung CK. Enhanced lovastatin production by solid state fermentation of Monascus ruber. Biotechnol Bioprocess Eng 2005;10(1):78-84.

19. Barrios-González J, Mejía A. Production of secondary metabolites by solid-state fermentation. Biotechnol Annu Rev 1996;2:85-121.

20. Thomas L, Larroche C, Pandey A. Current developments in solid-state fermentation. Biochem Eng J 2013;15(81):146-61.

21. Blais L, Desgagné A, LeLorier J. 3-Hydroxy-3-methylglutaryl coenzyme a reeducates inhibitors and the risk of cancer: A nested casecontrol study. Arch Intern Med 2000;160(15):2363-8.

22. Lewis KA, Holstein SA, Hohl RJ. Lovastatin alters the isoprenoid biosynthetic pathway in acute myelogenous leukemia cells in vivo. Leuk Res 2005;29(5):527-33.

23. Alexopoulos CJ, Mims CN, Blackwell M. Introductory Mycology. New York, USA: John Willey \& Sons Inc., Google Scholar; 1996.

24. Hajjaj H, Niederberger P, Duboc P. Lovastatin biosynthesis by Aspergillus terreus in a chemically defined medium. Appl Environ Microbiol 2001;67(6):2596-602.

25. Kumar MS, Kumar PM, Sarnaik HM, Sadhukhan AK. A rapid technique for screening of lovastatin-producing strains of Aspergillus terreus by agar plug and Neurospora crassa bioassay. J Microbiol Methods 2000;40(1):99-104.

26. Vilches-Ferrón MA, Casas-López JL, Sánchez-Pérez JA, Fernández-Sevilla JM, Chisti Y. Rapid screening of Aspergillus terreus mutants for overproduction of lovastatin. World J Microb Biotechnol 2005;21(2):123-5.

27. Babu RH, Rupa A, Radha S, Prasad NB, Narasimha G. Screening of lovastatin producing fungi by yeast growth inhibition assay method. J Pharm Res 2011;4(9):2967-8.

28. Nazzal S, Smalyukh II, Lavrentovich OD, Khan MA. Preparation and in vitro characterization of a eutectic based semisolid self-Nano emulsified drug delivery system (SNEDDS) of ubiquinone: Mechanism and progress of emulsion formation. Int J Pharm 2002;235:247-65.

29. Ghasemi-Mobarakeh L, Morshed M, Karbalaie K, Fesharaki M, Nasr-Esfahani MH, Baharvand H. Electrospun poly ( $\varepsilon$-caprolactone) nanofiber mat as extracellular matrix. Yakhteh 2008;10(3):179-84

30. Seenivasan A, Subhagar S, Aravindan R, Viruthagiri T. Microbial production and biomedical applications of lovastatin. Indian J Pharm Sci 2008;70(6):701-9.

31. Raper KB, Fennell DI. The Genus Aspergillus. Baltimore USA: Williams \& Williams Company, Baltimore Google Scholar; 1965.

32. Klich MA. Identification of Common Aspergillus Species. Utrecht, Netherlands: Centraalbureau Voor Schimmelcultures; 2002.

33. Gilman J. A manual of soil fungi. Soil Sci 1957;84(2):183.
34. Keller NP, Turner G, Bennett JW. Fungal secondary metabolism-from biochemistry to genomics. Nat Rev Microbiol 2005;3(12):937-47.

35. Prabhakar A, Krishnaiah K, Janaun J, Bono A. An overview of engineering aspects of solid state fermentation. Malays J Microbiol 2005;1(2):10-6.

36. Barrios-González J, Baños JG, Covarrubias AA, Garay-Arroyo A. Lovastatin biosynthetic genes of Aspergillus terreus are expressed differentially in solid-state and in liquid submerged fermentation. Appl Microbiol Biotechnol 2008;79(2):179-86.

37. Latha DP, Hemalatha KP. Production of lovastatin by Aspergillus flavipes NCIM 1209 using rice husk under solid state fermentation. Int J Adv Res Eng Appl Sci 2015;4(9):12-23.

38. Patil RH, Krishnan P, Maheshwari VL. Production of lovastatin by wild strains of Aspergillus terreus. Nat Prod Commun 2011;6(2):183-6.

39. Wei PL, Xu ZN, Cen PL. Lovastatin production by Aspergillus terreus in solid-state fermentation. J Zhejiang Univ Sci A 2007;8(9):1521-6.

40. Baranova NA, Kreiner VG, Egorov NS. The growth of Rhodotorula rubra yeasts and their synthesis of ergo sterol on media with lovastatin. Antibiot Khimioter 1996;41(11):3-6.

41. Nigam VK. Screening of different fungi for production of lovastatin. AJBPS 2015;5(44):24.

42. Lakshmanan D, Radha KV. An effective quantitative estimation of lovastatin from Pleurotus ostreatus using UV and HPLC. Int J Pharm Pharmsci 2012;4(4):462-4.

43. Ganiswara SG, Rianto S, Frans DS, Purwantyastuti. Farmakoligidan Tearpi. $5^{\text {th }}$ ed., Vol. 10. Jakarta: Bagain Farmakologi Kedokteram, UI; 1985. p. 643

44. Friedrich J, Žužek M, Benčina M, Cimerman A, Štrancar A, Radež I. High-performance liquid chromatographic analysis of mevinolin as mevinolinic acid in fermentation broths. J Chromatogr A 1995;704(2):363-7.

45. Morovján G, Szakács G, Fekete J. Monitoring of selected metabolites and biotransformation products from fermentation broths by high-performance liquid chromatography. J Chromatogr A 1997;763(1-2):165-72.

46. Javed S, Meraj M, Mahmood S, Hameed A, Naz F, Hassan S, et al. Biosynthesis of lovastatin using agro-industrial wastes as carrier substrates. Trop J Pharm Res 2017;16(2):263-9.

47. Mangunwardoyo W, Rafliyanti Y, Kusmana D. Bioprospection of lovastatin in Aspergillus spp. from university of Indonesia culture collection (UICC). World Appl Sci J 2012;16(2):183-8.

48. Osman ME, Khattab OH, Zaghlol GM, El-Hameed RA. Screening for the production of cholesterol lowering drugs (lovastatin) by some fungi. Aust J Basic Appl Sci 2011;5(6):698-703

49. Samiee SM, Moazami N, Haghighi S, Aziz-Mohseni F, Mirdamadi S, Bakhtiari MR. Screening of lovastatin production by filamentous fungi. Iran Biomed J 2003;7(1):29-33.

50. Gunde-Cimerman N, Friedrich J, Cimerman A, Benički N. Screening fungi for the production of an inhibitor of HMG CoA reductase: Production of mevinolin by the fungi of the genus Pleurotus. FEMS Microbiol Lett 1993;111(2-3):203-6.

51. Nidhiya K, Sathya E, Nitya M. Extraction and purification of lovastatin from non-aflatoxigenic strains of Aspergillus flavus. Int J Biol Pharm Res 2012;4:916-21.

52. Pansuriya RC, Singhal RS. Response surface methodology for optimization of production of lovastatin by solid state fermentation. Braz J Microbiol 2010;41(1):164-72.

53. Alarcón J, Aguila S, Arancibia-Avila P, Fuentes O, Zamorano-Ponce E, Hernández M. Production and purification of statins from Pleurotus ostreatus (Basidiomycetes) strains. Z Naturforsch C 2003;58(1-2):62-4.

54. Patel RP, Patel MM. Preparation and evaluation of inclusion complex of the lipid lowering drug lovastatin with?-cyclodextrin. Dhaka Univ J Pharm Sci 2007;6(1):25-36.

55. Suffness M, Pezzuto JM. Assays for cytotoxicity and antitumor activity. Methods Plant Biochem 1991;6:71-133.

56. Schmidmaier R, Simsek M, Baumann P, Emmerich B, Meinhardt G. Synergistic antimyeloma effects of zoledronate and simvastatin. Anticancer Drugs 2006;17(6):621-9.

57. Wong WW, Tan MM, Xia Z, Dimitroulakos J, Minden MD, Penn LZ. Cerivastatin triggers tumor-specific apoptosis with higher efficacy than lovastatin. Clin Cancer Res 2001;7(7):2067-75 